\title{
Complicated and uncomplicated acute type B aortic dissection: is an endovascular solution the "Holy Grail"?
}

\author{
Bradley G. Leshnower \\ Division of Cardiothoracic Surgery, Department of Surgery, Emory University School of Medicine, Atlanta, GA, USA \\ Correspondence to: Bradley G. Leshnower, MD. Associate Professor of Surgery, Division of Cardiothoracic Surgery, Emory University School of \\ Medicine, 1365 Clifton Rd NE, Suite A2213, Atlanta, GA 30322, USA. Email: bleshno@emory.edu.
}

Submitted Aug 02, 2021. Accepted for publication Oct 19, 2021.

doi: $10.21037 /$ acs-2021-taes-22

View this article at: https://dx.doi.org/10.21037/acs-2021-taes-22

\section{Introduction}

Thoracic endovascular aortic repair (TEVAR) has revolutionized the treatment of acute type B aortic dissection (ATBAD). Prior to endovascular therapy, patients would require either high-risk, emergent open descending thoracic aortic replacement for the treatment of rupture, or revascularization of an ischemic vascular bed via peripheral bypass without treatment of the central aortic pathology. Over the past two decades, TEVAR has become the primary therapy for complicated ATBAD and there is accumulating data suggesting that it should replace optimal medical therapy (OMT) as primary therapy for uncomplicated ATBAD. In this brief article we will summarize the current data regarding endovascular therapy for ATBAD.

According to the recent Society of Thoracic Surgeons/ Society for Vascular Surgery (STS/SVS) Consensus Reporting Standards document, complicated ATBAD is defined as an acute Type B dissection with evidence of rupture or malperfusion. It is well-established that TEVAR is the optimal therapy for complicated ATBAD. In contrast to open repair which carries a $29 \%$ operative mortality, TEVAR carries a $0-8 \%$ operative mortality with a $2-8 \%$ risk of stroke and a $2-6 \%$ risk of spinal cord ischemia (1-4). The only debate with respect to the treatment of complicated ATBAD pertains to the length of endovascular coverage. Our group has demonstrated that coverage from the left subclavian artery to the celiac carries a low risk of spinal cord ischemia and is highly effective in remodeling the aorta, with the majority of patients having complete thrombosis or obliteration of the entire thoracic aorta at one-year follow-up (2).

The more interesting debate revolves around the best treatment for uncomplicated ATBAD, where endovascular therapy is challenging the traditional first-line therapy of OMT. Although OMT produces excellent shortterm outcomes, there is a high failure rate in the chronic phase of ATBAD with intervention-free survival rates ranging between $40-50 \%$ at five years $(5,6)$. Accumulating data from high-volume aortic centers clearly shows that TEVAR can be performed with low morbidity and produce equivalent short-term survival and neurologic outcomes compared to OMT in uncomplicated ATBAD patients (7-9). In the Emory experience using TEVAR to treat fifty uncomplicated ATBAD patients, there was $100 \%$ survival, no renal failure, a single stroke, and two patients had transient paraparesis which had completely resolved by the time they ambulated out of the hospital.

With equivalent short-term outcomes, the remaining question is whether there is a long-term benefit of "prophylactic" TEVAR in uncomplicated ATBAD patients. Currently there is a paucity of level I evidence to answer this important question. The only existing prospective randomized trial is the Acute Dissection: Stent graft OR Best Medical Treatment (ADSORB) trial, which randomized patients with uncomplicated ATBAD to either OMT $(n=31)$ or OMT + TEVAR $(n=30)$. This trial demonstrated improved aortic remodeling but no difference in mortality with TEVAR at one year (7). Unfortunately, this trial was designed to examine outcomes at one year only, which is a premature timepoint to see a survival 
benefit from TEVAR. The only other relevant prospective randomized trial is the INSTEAD trial which randomized patients with subacute and chronic uncomplicated Type B Dissection to either OMT or OMT + TEVAR. In the initial report, there was no difference between TEVAR and OMT for the treatment of TBAD in all-cause mortality, aortic-related mortality, or progression of aortic disease at two-year follow-up, despite positive aortic remodeling in $>90 \%$ of the TEVAR patients. However, at five years (INSTEAD-XL), there was a significant reduction in disease progression and aortic-specific mortality in the TEVAR patients (10). In drawing conclusions from these two prospective randomized controlled trials combined with data from retrospective comparisons of TEVAR vs OMT for uncomplicated ATBAD, there appears to be a survival advantage with TEVAR which only becomes evident threefive years after the index procedure $(5,6,9,10)$.

\section{Conclusions}

In summary, TEVAR is widely accepted as the gold standard treatment for complicated ATBAD. There is growing data and momentum for endovascular therapy to be used as first-line therapy for uncomplicated ATBAD. A large, prospective trial randomizing uncomplicated ATBAD patients to either OMT or TEVAR with five-year follow-up would definitively answer the question. Financial support for such a trial remains elusive, as there is no incentive for industry to fund such a trial. A significant percentage of uncomplicated ATBADs are already being treated with TEVAR, and an equivocal or inferior outcome for TEVAR would be counterproductive to business. Currently there is no clear consensus on the optimal therapy for uncomplicated ATBAD amongst all aortic specialists within the cardiovascular community. Yet, there is a strong belief by aortic surgeons with endovascular expertise that TEVAR can be performed safely in this population, and that the subsequent aortic remodeling will prevent the need for future interventions for false lumen degeneration, prevent aortic rupture and ultimately improve survival. The accumulation of longer-term data will ultimately demonstrate that endovascular therapy is the "holy grail" for all acute type $\mathrm{B}$ aortic dissections.

\section{Acknowledgments}

Funding: None.

\section{Footnote}

Conflicts of Interest: The author has no conflicts of interest to declare.

Open Access Statement: This is an Open Access article distributed in accordance with the Creative Commons Attribution-NonCommercial-NoDerivs 4.0 International License (CC BY-NC-ND 4.0), which permits the noncommercial replication and distribution of the article with the strict proviso that no changes or edits are made and the original work is properly cited (including links to both the formal publication through the relevant DOI and the license). See: https://creativecommons.org/licenses/by-nc-nd/4.0/.

\section{References}

1. Trimarchi S, Nienaber CA, Rampoldi V, et al. Role and results of surgery in acute type $B$ aortic dissection: insights from the International Registry of Acute Aortic Dissection (IRAD). Circulation 2006;114:I357-64.

2. Lou X, Duwayri YM, Jordan WD Jr, et al. The Safety and Efficacy of Extended TEVAR in Acute Type B Aortic Dissection. Ann Thorac Surg 2020;110:799-806.

3. Hanna JM, Andersen ND, Ganapathi AM, et al. Five-year results for endovascular repair of acute complicated type B aortic dissection. J Vasc Surg 2014;59:96-106.

4. Bavaria JE, Brinkman W'T, Hughes GC, et al. Outcomes of Thoracic Endovascular Aortic Repair in Acute Type B Aortic Dissection: Results From the Valiant United States Investigational Device Exemption Study. Ann Thorac Surg 2015;100:802-8; discussion 808-9.

5. Lou X, Chen EP, Duwayri YM, et al. The Impact of Thoracic Endovascular Aortic Repair on Long-Term Survival in Type B Aortic Dissection. Ann Thorac Surg 2018;105:31-8.

6. Durham CA, Cambria RP, Wang LJ, et al. The natural history of medically managed acute type B aortic dissection. J Vasc Surg 2015;61:1192-8.

7. Brunkwall J, Kasprzak P, Verhoeven E, et al. Endovascular repair of acute uncomplicated aortic type $\mathrm{B}$ dissection promotes aortic remodelling: 1 year results of the ADSORB trial. Eur J Vasc Endovasc Surg 2014;48:285-91.

8. Iannuzzi JC, Stapleton SM, Bababekov YJ, et al. Favorable impact of thoracic endovascular aortic repair on survival of patients with acute uncomplicated type B aortic dissection. J Vasc Surg 2018;68:1649-55. 
9. Xiang D, Kan X, Liang H, et al. Comparison of mid-term outcomes of endovascular repair and medical management in patients with acute uncomplicated type B aortic dissection. J Thorac Cardiovasc Surg 2021;162:26-36.e1.

Cite this article as: Leshnower BG. Complicated and uncomplicated acute type B aortic dissection: is an endovascular solution the "Holy Grail"? Ann Cardiothorac Surg 2021;10(6):784-786. doi: 10.21037/acs-2021-taes-22
10. Nienaber CA, Kische S, Rousseau H, et al. Endovascular repair of type $\mathrm{B}$ aortic dissection: long-term results of the randomized investigation of stent grafts in aortic dissection trial. Circ Cardiovasc Interv 2013;6:407-16 